\title{
ВИДЫ И ФОРМЫ ДЕЯТЕЛЬНОСТИ ПРЕПОДАВАТЕЛЯ В СИСТЕМЕ ДИСТАНЦИОННОГО ОБРАЗОВАНИЯ СОВРЕМЕННОГО УНИВЕРСИТЕТА
}

\author{
Журавлева Ольга Ивановна \\ кандидат искусствоведения, профессор \\ Гуманитарно-педагогическая академия (филиал) \\ ФГАОУ ВО «Крымский федеральный университет \\ им. В.И. Вернадского»
}

\begin{abstract}
Аннотация: В статье рассматриваются новые виды и формы деятельности преподавателя, возникшие в системе дистанционного образования «Открытых университетов». Особое внимание уделяется влиянию информационно-коммуникационных технологий на формирование новой образовательной среды в современном вузе.
\end{abstract}

Ключевые слова: Образовательный стандарт, дистанционное образование, учебный процесс, информационно-коммуникативные технологии обучения.

\section{TYPES AND FORMS OF ACTIVITIES \\ OF THE TEACHER IN THE SYSTEM OF DISTANCE EDUCATION OF THE MODERN UNIVERSITY}

\section{Zhuravleva Olga Ivanovna}

\begin{abstract}
The article discusses new types and forms of teacher activity that have emerged in the distance education system of the Open Universities. Particular attention is paid to the influence of information and communication technologies on the formation of a new educational environment in a modern university.

Key words: Educational standard, distance education, educational process, information and communication technologies of education.

Изложение основного материала статьи. С момента создания первого «Открытого университета» (1969) в Лондоне система образования on-line прочно вошла в европейское и мировое пространство высшей школы. Однако только с момента стремительного распространения сети Интернет - (Word,
\end{abstract}


Wide, Web - WWW) открытое дистанционное образование окончательно утвердилось в мире, создав возможность любому желающему получить высшее профессиональное образование и иметь возможность повышать квалификацию на протяжении всей профессиональной карьеры. В качестве примеров дистанционного образования можно привести высшую школу в Израиле, Нидерландах, Австралии и ряде других стран.

Система on-line или, дистанционного обучения (ДО) (как принято ee определять в отечественном высшем образовании) - одна из наиболее перспективных систем подготовки специалиста с учетом не только профессионально - технологических, но и социально - культурных традиций национального и глобального уровня. На протяжении многих десятилетий, отсутствие широкого взаимообмена отечественной высшей школы с важнейшими достижениями в областях образования, информационной и компьютерной технике и технологии, создали существенный тормоз в развитии дистанционного образования. К этому необходимо также добавить - разные национальные и государственные системы образования, активное развитие частного предпринимательства, ограниченность обмена опытом в научной и практической деятельности многих вузов нашей страны. Но, при всех трудностях, данных процесс активно развивается и преодолевает сложности в очень короткий срок. За последнее время в отечественной высшей школе появились инновационные методы и технологии, позволяющие существенно повысить эффективность образования. Начало активному развитию этому процессу было положено постановлением, «О внесении изменений в закон Российской федерации «Об образовании» в части применения электронного обучения, дистанционных образовательных технологий», принятым и ратифицированным в феврале 2012 года [1]. В его основных положениях подчеркивалось:

- взаимодействие участников образовательного процесса предусматривает обязательное внедрение различных систем, методов и и технологий дистанционного обучения.

- изменения могут применяться при реализации образовательных программ независимо от форм получения образования;

- электронное обучение предусматривает организацию образовательного процесса с применением компьютерных программ, информационно-коммуникативных технологий обеспечивающих ее обработку и передачи по линиям связи. 
Так был начат процесс активного внедрения дистанционного обучения в отечественное образование на всех уровнях.

Исследованию технологий on-line посвящено большое количество работ, где зарубежные авторы по праву занимают первое место. И это обусловлено полувековой активной и стабильной работой «Открытых университетов». Среди них следует назвать работы: Т. Андерсона, М. Аллена, Дж.Боата, Р. Деллинга, Д. Гуллера, Д. Кигана, Д. Кигана, М. Мура, О. Петерса. Г. Рамбла, К. Смита и др. большая часть которых представляет собой учебники по руководству работой в условиях on-line определенной национальной системы образования или конкретного ведущего университета.

Активное развитие системы дистанционного образования, ее внедрение организацию и управления учебным процессом современной высшей школы разных стран мира существенно трансформировала понимание роли, места и функций преподавателя в вузе.

Недооценка значимости этой проблемы, неизбежно приводят к значительному снижению качества образовательного процесса в подготовки студентов.

Ни один современный вуз не может обойтись без опытного коллектива преподавателей в проектировании и создании информационной образовательной среды. В этих условиях, особое внимание следует уделить проблеме признания качественно новой роли преподавателя вуза в рамках дистанционного обучения студентов.

Для любого преподавателя это связано с особыми условиями профессиональной деятельности - повышением профессиональной компетентности в области информационных и компьютерных методов и технологий, подготовкой и размещением учебного и методического материала в системе LMS, разработкой новых элективных курсов для расширения профессиональных компетенций, управлением самостоятельной работой студентов в виртуальном образовательном пространстве учебного процесса. Достижение поставленных целей в дистанционном образовании возможно только в условиях перестройки всех уровней обучения вуза, целенаправленного и четкого внедрения в ее системы on-line, а также понимания преподавателей своей новой роли и значения в проектировании и реализации учебного процесса.

С появлением методов и технологий открытого дистанционного образования в сфере высшей школы, произошли существенные изменения в 
деятельности преподавателей, их профессиональной и учебной функции. Коснемся некоторых причин данного явления:

- усложнение деятельности в трансформации нормативных и разработке новых дисциплин;

- необходимость приобретения специальных навыков и приемов в работе над учебными курсами;

- значительное повышение требований к уровню и качеству учебных материалов, предлагаемых студентам;

- возрастание роли студента, его участия в учебном процессе и разработке дидактического материала;

- усиление функции поддержки студента преподавателем в работе над материалами дисциплин;

- появление новой, вариативной части образовательной программы, и соответствующей ей системы элективных дисциплин. Цель их - разработка дополнительных обучающих компетенций, установленных вузом дополнительно к компетенциям образовательного стандарта по специальности;

- широкое и гибкое развитие обратной связи преподавателя с каждым обучающимся

Одновременно с этим, следует обратить внимание, что в современных условиях новые информационные методы и технологиями не заменят педагога в вузе, а лишь создадут ему более гибкие условия работы с обучающимися от части изменив его функции. Так, в традиционном аудиторной системе организации учебного процесса преподаватель большую часть времени отдавал непосредственному чтению лекций, то в образовании, построенном на современных компьютерных и телекоммуникационных системах, открывается возможность строить обучение в альтернативных формах свободного общения.

В современных условиях преподаватель высшей школы имеет право:

- в составлении материалов учебных занятий свободно ориентироваться в обширной научной и учебной информации интернет пространства;

- общаться и работать со студентами в виртуальном пространстве без жесткого регламента отведенного времени;

- вырабатывать индивидуальную образовательную траекторию, согласно интересам каждого студента [9].

И так, разработка различных материалов в условиях новых цифровых технологий требует от преподавателя вуза педагогического мастерства 
владения предметом курса, но и свободного владения современными информационными технологиями, без которых высшая школы существовать уже не может. Это же касается общения преподавателя со студентами при освоении обширных образовательных ресурсов. Отмеченные выше коммуникативные технологии взаимодействие также требует специальных не только педагогических, но и технологических навыков, опыта работы с современными техническими средствами.

Рассмотрим наиболее важные профессиональные роли функции преподавателя вуза в условиях дистанционного образования.

Преподаватель - организатор и консультант. Прежде всего, роль преподавателя современного вуза связана с непосредственным процессом обучения студентов, соответствующих ему формам контроля оценки качества приобретенных знаний, умений и навыков студентов в рамках строгого контролю успешности выполнения учебного плана и графика. В данной роли преподаватель излагает материал курса и контролировать процесс обучения. В данных условиях, преподаватель еще и оказывает помощь студентам, консультируя их в работе над методическим материалом курса. Таким образом, его задача - организовать обратную связь с обучающихся в процессе их обучения [6].

Преподаватель - тьютор - очень важная и распространённая функций в организации дистанционного обучения. В целом, она связана с полным сопровождением обучающихся на протяжении всего процесса обучения. Вот одно из определений данного термина, которое гласит что тьютор (от англ, tutor - репетитор, куратор, воспитатель в образовательном учреждении) и преподавательская должность в некоторых университетах.

Очень значительны и важны функции куратора как педагога организатора самостоятельной внеаудиторной работы студентов, а также педагога - руководителя по обучающегося по индивидуальным планам. Таким образом - основная задача тьютора - организация, сопровождение обучения и контроля студента в особых условиях индивидуальных планов и графиков.

Особая методика работы педагога - тьютера разработана в системе творческих профессий, где он является преподавателем индивидуальной студийной или исполнительской работы с обучающимися и требует непосредственного контакта. В данном случае тьютер является педагогом по индивидуальной работе в студии, исполнительском классе или театральной сцене. Так возникает смешанный тип обучение, где компьютерные технологии 
выполняют совсем другие функции (видео, аудио записи для повторного просмотра и т.п.).

Педагог - фасилитатор (организатор, координатор). Организация учебного процесса как самостоятельной деятельности сформировала в западной традиции профессию педагога - фасилитатора, цели и задачи которой - помощь и координация процесса обучения студента в различных формах ее существования [3].

Собственно, она соприкасается с работой тьютера и, одновременно с этим, существенно от нее отличается. Если тьютер выполняет функции преподавателя-консультанта, то фалиситатор - организатора широкого спектра деятельности. вплоть до организации жизни и досуга обучающихся. В его обязанности входит следить за своевременным выполнением расписания занятий и графиком выполнения заданий, осуществлять координацию со всеми участниками обучения, осуществлять консультационную поддержку в деловых вопросах и организовывать быт и досуг студента.

В целом, данная профессия требует от преподавания коммуникативных качеств, умения быстро реагировать на любые события, организовывать регламента действий, хорошего знания логики процесса обучения.

Педагог - инвингилатор (модератор, консультант) (дословно, от англ. Invigilator - экзаменатор, следящий за тем, чтобы студенты не списывали во время экзаменов). Одна из самых молодых и инновационных форм деятельности педагога высшей школы, объединяющих несколько ролей и функций в одно понятие. Педагог - инвингилатор - это и обучающий преподаватель - консультант, и тьютер, и фасилитатор с различными функциями. Однако, его основная деятельность связана с дистанционного обучения. В его обязанности входит обеспечить процесс обучения и контроля знаний по программе дистанционного курса, направленной на знание компьютерных программ, владения ими в процессе обучения, активное использование в практической работе.

Педагог - инвингилатор очень часто осуществить процесс взаимосвязи и общения участников в режиме телеконференции или форума, а также других Web - форм учебной и научно-исследовательской работы необходимой студенту особенно на 1,2-м курсах бакалавриата. В данном случае речь идет об очень важной работе преподавателя в качестве модератора.

Педагог - инвингилатор также может выполнять другие более узкие и конкретные формы дистанционного процесса обучения, связанные с помощью 
студенту в поисках интернет - материала для подготовки к открытому диалогу с преподавателем и коллегами по вопросам курса или научной проблемы. Чаще всего это является его непосредственной функциональной обязанностью при проведении дистанционного обучения.

Подводя итог, также следует подчеркнуть необходимость работы каждого педагога над повышением профессиональной компетентности, мастерства и инициативы в постижении новых информационных технологий современного образовательного процесса.

Преподаватели в дистанционном обучении также выполняют огромное количество деятельности как диагносты, исследователи, организаторы, менеджеры и консультанты. Следовательно, являясь организаторами образовательного процесса, они выступают в роли коммуникативного партнера своих обучающихся.

Несмотря на все сложности процесса изменений в высшем образовании сегодня, они влекут за собой усиление эффективности профессиональной деятельности преподавателя профессиональной подготовке студентов, а значит и конкурентоспособности высшей школы высшего в целом.

Выводы. И так, как показал анализ основных характеристик системы дистанционного открытого образования, сегодня в российской высшей школе оно рассматривается скорее как процесс, чем - результат или продукт. В этом заложены причины сложной адаптации новых ролей и функция преподавателя, сложившихся в мировой образовательной практики как профессиональные направления деятельности. Тем не менее, опыт многих отечественных университетов, включая Крымский федеральный университет и его филиалы, свидетельствует о необратимом процессе реформирования отечественного образования. Только такой стратегический путь реформ приведет к качественным результатам в областях демографического, социальноэкономического и культурного развития современного общества.

\section{Список литературы}

1. Федеральный закон от 29.12.2012 N 273-Ф3 (ред. от 02.03.2016) «Об образовании в Российской Федерации» [Электронный ресурс] // Консультант Плюс. URL: https://www.consultant.ru/document/cons_doc_LAW_140174/9ab 9b85 e5291f25d6986b5301ab79c23f0055ca4/ 
2. Федеральный государственный образовательный стандарт высшего профессионального образования по направлению подготовки 050100 «Педагогическое образование» с квалификацией (степенью) «бакалавр». Министерство образования и науки Российской Федерации. 17.01.2011 № 46. URL: http://www.edu.ru/db/mo/Data/d_11/ m46.html (дата обращения: 12.07.13).

3. Грицкевич Е. В. Фасилитаторский стиль педагога профессионального обучения: Содержание и организационно-педагогические условия его становления //file:///C:/Users/Acer/Desktop/fasilitatorskiy-stil-pedagoga-professiona lnogo-obucheniya-soderzhanie-i-organizatsionno-pedagogicheskie-usloviya-egostanovleniya.pdf

4. Журавлева О. И. Перспективы развития дистанционных технологий открытого образования в современной высшей школе // Проблемы современного педагогического образования. - Сборник научных трудов: Ялта: РИО ГПА, 2019. - Вып. 63. - Ч. 1. - С. 115 -118.

5. Осипова Л.Б.Дистанционное обучение в вузе: модели и технологии // Л.Б. Осипова, О.М. Горева. Современные проблемы науки и образования. 2014. - № 5. URL: http://science-education.ru/ru/article/view?id=14612

6. Пельменев В.К, Лукашеня 3.В. Теоретические основы реализации консалдинговой профессиональной деятельности преподавателя вуза file:///C:/Users/Acer/Desktop/teoreticheskie-osnovaniya-realizatsii-konsaltinga-pro fes sionalnoy-deyatelnosti-prepodavatelya-vuza.pdf

7. Челнокова Е.А., Тюмасева 3.И. Тьютерская деятельность в дистанционном обучении // «Вестник Мининского универ.» 2016 -№ 3. file:///C: / Users/ Acer/ Desktop/tyutorskaya-deyatelnost-v-distantsionnom-obuc henii. pdf

8. Юхвид Е.Н. Информационно-коммуникативная система общества и образовательная среда: социально-философские аспекты. Социальное образование и кадровое обеспечение социальной сферы/Материалы VIII Всероссийского социально-педагогического конгресса. Изд-во РГСУ, М., 2008. T. II.

9. Zhuravleva O. Multimedia technologies in on-line training system of musician teacher. https://www.shsconferences. org/articles/shsconf/abs/2020/15/ shsconf_ictp2020_00110/shsconf_ictp2020_00110.html. 